\title{
Effect of population size on the mating system in a self-compatible, autogamous plant, Aquilegia canadensis (Ranunculaceae)
}

\author{
MATTHEW B. ROUTLEY $\dagger$, KATHERINE MAVRAGANIS \& CHRISTOPHER G. ECKERT* \\ Department of Biology, Queen's University, Kingston, Ontario, Canada K7L 3N6
}

\begin{abstract}
In self-compatible plants, small populations may experience reduced outcrossing owing to decreased pollinator visitation and mate availability. We examined the relation between outcrossing and population size in eastern Ontario populations of Aquilegia canadensis. Experimental pollinations showed that the species is highly self-compatible, and can achieve full seed-set in the absence of pollinators via automatic self-pollination. We estimated levels of outcrossing $(t)$ and parental inbreeding coefficients $(F)$ from allozyme variation in naturally pollinated seed families for 10 populations ranging in size from 32 to 750 reproductive individuals. The proportion of seeds produced through outcrossing was generally low (mean $=0.29 \pm 0.02 \mathrm{SE}$ ) and varied widely among populations (range $=0.00-0.83$ ). Accordingly, estimates of $F$ were large (mean $=0.26 \pm 0.05$ ) and significantly greater than zero in seven populations. As expected, four small populations $(N<40)$ outcrossed less $(0.17 \pm 0.03)$ than six large populations $(N>90 ; 0.38 \pm 0.03)$. However, parental plants were not significantly more inbred in small than large populations $(P=0.18)$. There was no difference in the germination of seeds from hand self- and cross-pollinations. However, population genetic estimates of inbreeding depression for survival expressed from seed to reproductive maturity were very high (mean $\delta=1-$ relative fitness of selfed seed $=0.88 \pm 0.14$ ). The combination of self-compatibility and automatic self-pollination makes the mating system of $A$. canadensis sensitive to variation in ecological factors that affect the likelihood of cross-pollination.
\end{abstract}

Keywords: Aquilegia canadensis, autogamy, inbreeding depression, mating systems, population size, self-fertilization.

\section{Introduction}

In self-compatible, cosexual plants, the level of outcrossing is likely to be influenced by factors that determine the relative amounts of self and outcross pollen deposited on stigmas (Lloyd, 1980). In particular, the size and spatial structure of populations may affect the delivery of outcross pollen by influencing pollinator visitation (e.g. Sih \& Baltus, 1987) and the availability of conspecific pollen donors (Lloyd, 1980). Ecological effects on the mating system may be especially pronounced in species that possess some means of automatic self-pollination. If local conditions are such that outcross pollen does not arrive on stigmas promptly, ovules will be self-fertilized by default.

*Correspondence. E-mail: eckertc@biology.queensu.ca

$\dagger$ Present address: Department of Botany, University of Guelph, Guelph, Ontario, Canada NIG ZWI.
Wide variation in the level of outcrossing among populations may have manifold effects on key evolutionary parameters, such as the distribution of genetic diversity (Hamrick \& Godt, 1990), population and individual fitness (Charlesworth \& Charlesworth, 1987), response to natural selection (Charlesworth, 1992) and, ultimately, the likelihood of speciation (Barrett, 1990). Recently, there has been renewed interest in how the mating system is affected by aspects of population structure, because human-induced alterations to natural habitat often reduce the size and density of populations (Ellstrand \& Elam, 1993; Schemske et al., 1994). Experimental work on many species has shown that progeny produced by selfing are usually inferior to those produced by outcrossing (Husband \& Schemske, 1996). Consequently, decreased outcrossing in small, sparse populations may reduce population fitness, potentially increasing the probability of extinction (Ellstrand \& Elam, 1993). However, despite the ecological, genetic 
and evolutionary significance of variation in population size, few studies have attempted to quantify both the strength of inbreeding depression as well as the extent to which outcrossing covaries with population size (e.g. Van Treuren et al., 1993; Bijlsma et al., 1994).

In this study, we describe the sexual system, quantify levels of outcrossing and inbreeding depression, and determine the extent to which outcrossing covaries with population size in eastern columbine, Aquilegia canadensis L. (Ranunculaceae). This is a spring-flowering, short-lived perennial found in small, patchy populations on rock outcrops and dry woods in eastern central North America. The large, red, nodding flowers consist of 4-5 unfused carpels with styles surrounded by and extending beyond a column of 30-40 stamens that dehisce over a 3-day period. Petals form $25-35 \mathrm{~mm}$ nectar spurs, and sepals flare out in a bright red skirt around the spur openings. Bright red coloration and copious, dilute nectar (25\% sucrose, Macior, 1978) suggests that flowers are adapted to pollination by hummingbirds (Grant \& Grant, 1968), although bumble bees (Bombus spp.) appear to be the most common pollinator in eastern Ontario.

Large investment in attractive structures and nectar suggests that flowers of $A$. canadensis are adapted for outcrossing. However, flowers can set seed automatically when isolated from pollinators (Macior, 1978; Eckert \& Schaefer, 1998). Despite early reports that $A$. canadensis is protogynous (Schneck, 1901), an analysis of pollen tube growth after controlled pollination in two populations clearly indicates that there is complete overlap of stigma receptivity and anther dehiscence within flowers (C. G. Eckert \& K. Mavraganis, unpubl. ms.). In addition, self-pollination is promoted by the close proximity of anthers and stigmas (Eckert \& Schaefer, 1998). Aquilegia canadensis appears therefore to have a 'facultatively xenogamous' sexual system (Cruden \& Lyon, 1989); flowers seem adapted for outcrossing but can self-fertilize if insufficient outcross pollen is deposited for full seed-set.

Although automatic self-pollination is often interpreted as an adaptation for reproductive assurance (Eckert $\&$ Schaefer, 1998), it is likely to make the mating system sensitive to variation in ecological factors like population size that might influence the level of cross-pollination. Decreased outcrossing and consequent inbreeding depression in small populations may, in part, explain positive correlations between population size and components of fitness observed among eastern Ontario populations of A. canadensis (K. Mavraganis \& C. G. Eckert, unpubl. ms.)
This study has four objectives. (i) We used experimental pollinations to confirm earlier reports that A. canadensis is highly self-compatible and autofertile. (ii) We then assayed allozyme variation in progeny arrays to investigate whether the capacity of flowers for automatic self-pollination is associated with self-fertilization in naturally pollinated flowers. (iii) We compared outcrossing rates and inbreeding coefficients between small and large populations to test the hypothesis that small populations experience reduced outcrossing. (iv) We estimated the strength of inbreeding depression by comparing observed and expected inbreeding coefficients to assess the fitness consequences of self-fertilization, and to determine whether covariation between the mating system and population size might explain the positive correlation between population size and reproductive output observed among populations in eastern Ontario.

\section{Materials and methods}

\section{Study populations}

We studied 10 populations ranging in size from 32 to 750 plants located in eastern Ontario, Canada (Table 1). Eight were from the Admiralty Islands in the St Lawrence River near Gananoque. Another (CLR) was located on the boundary of Charleston Lake Provincial Park, about $3 \mathrm{~km}$ north-east of the town of Outlet. The remaining population (WMZ) was located at the Queen's University Biological Station, about $2 \mathrm{~km}$ west of Chaffey's Lock. Populations were usually spatially discrete and separated from nearby populations by at least $100 \mathrm{~m}$, usually much more. All populations occurred on exposed rock outcrops with little tree or shrub cover.

The size of each population $(N)$ was estimated as the number of reproductive individuals at peak flowering (Table 1). Seven were surveyed in 1995, 1996 and 1997. Population WMZ was only surveyed in 1996. To test for an association between $N$ and mating system parameters, populations were classified as either large $(N>90, n=6)$ or small $(N<40$, $n=4$ ) on the basis of their size in 1995 (1996 for WMZ). The large-size class represents the upper quartile of the distribution of population sizes in eastern Ontario. The small-size class represents the smallest size of population for which one can obtain enough seed families to estimate the mating system accurately. Although there was some fluctuation in the size of each population between years, relative size was strongly correlated between years (Kendall's 
Table 1 The 10 populations of Aquilegia canadensis sampled for this study. Population size was estimated as the number of reproductive individuals during peak flowering. Populations not surveyed during a given year are indicated by 'na'

\begin{tabular}{llrrr}
\hline & & \multicolumn{3}{c}{ Population size } \\
\cline { 3 - 5 } Population & Code & 1995 & 1996 & 1997 \\
\hline Charleston Lake & CLR & 750 & 181 & 768 \\
Queen's University & WMZ & na & 200 & na \\
$\quad$ Biology Station & & & & \\
Aubrey Island & AUB & 138 & 201 & 212 \\
Juniper Island & JUN & 121 & 165 & 194 \\
MacDonald Island-1 & MC1 & 105 & 66 & 77 \\
Moneysunk Island & MYS & 91 & 97 & 109 \\
MacDonald Island-2 & MC2 & 40 & na & na \\
Anchorage Island & ANC & 35 & 110 & 87 \\
Camelot Island & CLR & 35 & na & 32 \\
Black Duck Island & BLD & 32 & 62 & 55 \\
\hline
\end{tabular}

coefficient of concordance: $W=0.921, P=0.011$ ). The populations that were classified as small in 1995 and subsequently resurveyed stayed small in the following years, except ANC which more than doubled in size from 1995 to 1997 (Table 1).

\section{Self-compatibility and autofertility}

Self-compatibility and the capacity for automatic selffertilization were assessed in the largest population (CLR) in 1995. We randomly chose 39 plants, each with at least three unopened flowers, and excluded them from pollinators with a wire mesh cylinder covered with fine bridal veil. For each plant, one bud was randomly assigned to each of three treatments: self-pollinated, cross-pollinated or unpollinated. Because some buds did not mature into flowers, some plants did not receive all three treatments. Flowers were self-pollinated within $12 \mathrm{~h}$ of when the first anther started shedding pollen (i.e. at the onset of stigma receptivity) by brushing all stigmas with fresh pollen from three anthers taken from the same flower or a different flower on the same inflorescence. Flowers were cross-pollinated in the same fashion less than $12 \mathrm{~h}$ before the first anther started shedding pollen using one anther from each of three different pollen donors growing about $2 \mathrm{~m}$ away. To avoid contaminating the stigmas of cross-pollinated flowers with self-pollen, all anthers were removed before they started to shed pollen. The removal of anthers from flowers at this stage does not reduce seed production (Eckert \& Schaefer, 1998). To control for any potential negative effects of anther removal on seed weight and/or viability, we also removed all anthers from flowers immediately after self-pollination. Flowers were left unpollinated to assess their capacity for automatic selffertilization. Results from a subsequent experiment showed that $A$. canadensis is not apomictic, and that pollinators do not get into the exclusion cages (Eckert \& Schaefer, 1998). To determine whether the proximity of anthers to stigmas influences the capacity for automatic self-fertilization, the distance between the stigma of the shortest style and the tip of the anther on the longest stamen on unpollinated flowers was measured to $0.1 \mathrm{~mm}$ using calipers just after the last anther had started shedding pollen. The filaments of all anthers are still fully turgid at this point.

We collected fruits just as the follicles started to split open. Viable seeds are plump, black and glossy, and easily distinguished from aborted seeds or unfertilized ovules. The viable seeds in each fruit (defined here as all the follicles maturing from the same flower) were counted and weighed as a group to $1 \mathrm{mg}$. The number of carpels/ flower varies between four and six in this population, and the number of seeds per fruit correlates positively with carpel number. Accordingly, we expressed seed production on a per carpel basis. Because all treatments were applied to most plants, we assessed the effect of pollination treatment on seeds/carpel and seed mass using repeated-measures ANOVA with plants as subjects and pollination treatment as a fixed, within-subject effect (Neter et al., 1990, pp. 1037-1047). Only the 25 plants that received at least two treatments were included in this analysis. We contrasted treatment means with paired $t$ tests and used sequential Bonferroni correction to hold the experiment-wise Type I error rate at 5\%.

\section{Pollen and ovule production}

The ratio of pollen to ovule production is widely used as a conservative indicator of the mating system in flowering plants (Cruden, 1977). We estimated pollen and ovule production for 50 randomly selected plants from a $1-\mathrm{km}^{2}$ area around but not including population WMZ. Up to the first four flowers on each plant $(n=160$ in total) were collected just before anther dehiscence and the ovules and anthers in each were counted. Ovules were counted in all carpels in each flower. Pollen grain number was quantified for all anthers in each flower using a haemocytometer following Eckert \& Barrett (1994a).

\section{Mating-system estimation}

Two fruits were sampled from each of up to 50 plants in each population in 1995 (1996 in WMZ). The seeds from all follicles in each fruit were pooled, counted and stored at $5^{\circ} \mathrm{C}$ until they were assayed for allozyme variation in the summer of 1997. 
Allozyme variation was assayed using horizontal starch gel electrophoresis following Wendel \& Weeden (1991). Seeds were crushed in $25 \mu \mathrm{L}$ of an extraction buffer consisting of $10 \mathrm{~mm}$ dithiothreitol and $0.025 \%$ w/v polyvinylpyruvate in $0.1 \mathrm{M} \mathrm{pH} 7.5$ Tris- $\mathrm{HCl}$ buffer. The slurry was absorbed onto $2 \times 10 \mathrm{~mm}$ chromatography paper wicks (Whatman $3 \mathrm{MM}^{\mathrm{TM}}$ ) which were inserted $2.5 \mathrm{~cm}$ from the cathodal end of $11 \%$ starch gels measuring $15 \times 20 \times 1.5 \mathrm{~cm}$. Gels were then subjected to constant voltage until a dye marker (Club House $^{\mathrm{TM}}$ green food colouring) moved $9 \mathrm{~cm}$ from the origin. Using seed from 20 populations in eastern Ontario, we screened 16 enzymes for electrophoretic variation at 30 putative loci, of which seven showed variability. However, band phenotypes could be clearly resolved and interpreted for only two loci: isocitrate dehydrogenase (IDH, EC 1.1.1.42) assayed on the morpholine-citrate pH 6.1 buffer system (at $50 \mathrm{~mA} /$ $150 \mathrm{~V}$ ), and peroxidase (PER, EC 1.11.1.7) on the lithium-borate $\mathrm{pH} 8.3$ buffer system (at $60 \mathrm{~mA} / 150 \mathrm{~V}$ ). Two alleles were detected for each locus. Mendelian segregation of the alleles at each locus was confirmed by assaying hand self-fertilized progenies (K. Mavraganis \& C.G. Eckert, unpubl. data). Ten randomly chosen seeds were assayed from a single randomly chosen fruit from each of 30 naturally pollinated maternal plants in CLR and 24 plants in WMZ. For each of the other populations, five seeds were assayed from a single randomly chosen fruit for each of 30 plants per population. Five progeny per family is sufficient to allow accurate estimation of mating system parameters when the average level of outcrossing is low $(t<0.5$; K. Ritland, pers. comm.), as it turned out to be in the populations studied here.

Single-locus and multilocus outcrossing rates $\left(t_{\mathrm{s}}\right.$ and $t_{\mathrm{m}}$, respectively), the parental fixation index $(F)$, and pollen and ovule allele frequencies (Table 2) were estimated from progeny genotypes using the maximum likelihood computer program MLTR (version 0.9; Ritland, 1986) with Newton-Raphson iteration. For each population, iterations from several different starting values of $t$ and $F$ converged on the same estimate. Standard errors were calculated as the standard deviation of 1000 bootstrap values for each estimate generated using the progeny array as the unit of re-sampling. Biparental inbreeding was estimated by subtracting the average of the single-locus estimates of $t$ from the multilocus estimate (Brown, 1990).

For all parameters, differences between populationsize classes were evaluated by comparing the distributions of average bootstrap values. If $x_{i j k}$ is the $k$ th of 1000 bootstrap estimates of a parameter for the $j$ th of $n_{i}$ populations of the $i$ th size class, 1000 average bootstraps for each population-size class were calculated as:

$x_{i+k}=\frac{1}{n_{i}} \sum_{j=1}^{n_{i}} x_{i j k}$

Comparisons were considered significant if $95 \%$ of the differences between average bootstrap values $\left(x_{1+k}-\right.$ $x_{2+k}$ ) were above zero for a one-tailed test (e.g. $\mathrm{H}_{\mathrm{A}}$ : $x_{1}>x_{2}$ ), or if $97.5 \%$ were either above or below zero for a two-tailed test $\left(\mathrm{H}_{\mathrm{A}}: x_{1} \neq x_{2}\right)$.

\section{Inbreeding depression}

Inbreeding depression for seedling emergence was quantified under greenhouse conditions by comparing emergence of selfed and outcrossed seeds generated from hand-pollinations in CLR. One fruit was available for each treatment on each plant, and the seeds from all follicles in each fruit were pooled. Two replicate samples

Table 2 Estimated pollen and ovule allele frequencies ( $\pm \mathrm{SE}$ ) at two allozyme loci (IDH and $P E R$ ) in 10 populations of Aquilegia canadensis. For both loci, the frequency of the most anodally migrating allele is presented. na, not applicable. Populations are listed in order of decreasing size (see Table 1)

\begin{tabular}{|c|c|c|c|c|}
\hline \multirow[b]{2}{*}{ Population } & \multicolumn{2}{|c|}{$I D H$} & \multicolumn{2}{|c|}{$P E R$} \\
\hline & Pollen & Ovule & Pollen & Ovule \\
\hline WMZ & $0.810 \pm 0.059$ & $0.854 \pm 0.047$ & $0.206 \pm 0.048$ & $0.229 \pm 0.069$ \\
\hline AUB & $0.601 \pm 0.188$ & $0.600 \pm 0.072$ & $0.173 \pm 0.165$ & $0.217 \pm 0.060$ \\
\hline JUN & $0.789 \pm 0.057$ & $0.800 \pm 0.056$ & $0.264 \pm 0.053$ & $0.317 \pm 0.072$ \\
\hline MC2 & na & $0.833 \pm 0.062$ & na & $0.267 \pm 0.066$ \\
\hline ANC & $0.265 \pm 0.139$ & $0.733 \pm 0.070$ & $0.330 \pm 0.128$ & $0.167 \pm 0.049$ \\
\hline CAM & $0.457 \pm 0.119$ & $0.845 \pm 0.058$ & $0.326 \pm 0.106$ & $0.207 \pm 0.056$ \\
\hline BLD & $0.927 \pm 0.109$ & $0.683 \pm 0.071$ & $0.018 \pm 0.063$ & $0.050 \pm 0.027$ \\
\hline
\end{tabular}

(C) The Genetical Society of Great Britain, Heredity, 82, 518-528. 
Table 3 Analysis of variation in seed number and seed mass between pollination treatments in Aquilegia canadensis. Individual values for seeds/carpel and seed mass were entered in repeated-measures ANOVAs with plant as subject and treatment as a fixed within-subject effect. Treatment means are in Fig. 1

\begin{tabular}{lrrrc}
\hline Source of variation & d.f. & SS & $F$ & $P$ \\
\hline Seeds/carpel & & & & \\
$\quad$ Model $\left(r^{2}=0.68\right)$ & 26 & 1173 & 3.4 & 0.0002 \\
$\quad$ Plant & 24 & 1066 & 3.4 & 0.0003 \\
$\quad$ Treatment & 2 & 120 & 4.6 & 0.0164 \\
$\quad$ Residual & 41 & 541 & & \\
Seed mass & & & & \\
$\quad$ Model $\left(r^{2}=0.83\right)$ & 26 & 0.93 & 7.3 & $<0.0001$ \\
$\quad$ Plant & 24 & 0.84 & 7.2 & $<0.0001$ \\
$\quad$ Treatment & 2 & 0.10 & 10.3 & 0.0002 \\
$\quad$ Residual & 40 & 0.20 & & \\
\hline
\end{tabular}

of 20 seeds/treatment/plant for each of 19 plants were sown into $5.7-\mathrm{cm}$ pots filled with Sunshine $\mathrm{Mix}^{\mathrm{TM}}$ no. 1 . Pots were randomized on a greenhouse bench and emergence was monitored regularly. Once a seedling exposed both cotyledons, it was counted and removed. The difference between selfed and outcrossed seed in the proportion emerging within six months was assessed by averaging the two replicate pots for each plant and performing a one-tailed paired $t$-test.

Inbreeding depression ( $\delta=1$ - fitness of selfed progeny/fitness of outcrossed progeny) for survival from seed to reproductive maturity was calculated from the estimated outcrossing rates $(t)$ and parental inbreeding coefficients $(F)$ using Ritland's (1990) equilibrium estimator:

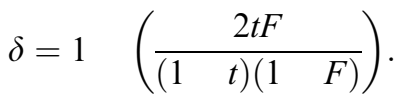

Because estimates of biparental inbreeding were very low (see below), estimates of $\delta$ were not corrected for crossing among relatives. Statistical departures of the estimates from 0 and 0.5 were assessed by examining the distributions of 1000 bootstrap values as above.

\section{Results}

\section{Self-compatibility and autofertility}

There was significant heterogeneity in seed production among plants and pollination treatments (Table 3, Fig. 1). All treatments resulted in substantial seed, although outcrossed (X) flowers set $18 \%$ more seeds/ carpel than either selfed (S) or unmanipulated (U) flowers. Multiple contrasts revealed significant differences between $\mathrm{X}$ vs. $\mathrm{S}$ (paired $t_{\mathrm{p}}=2.7$, one-tailed $P=0.0082)$ and $\mathrm{X}$ vs. $\mathrm{U} \quad\left(t_{\mathrm{p}}=2.1\right.$, one-tailed $P=0.026)$ but not $\mathrm{S}$ vs. $\mathrm{U}\left(t_{\mathrm{p}}=0.3\right.$, one-tailed $P=0.40)$. Stigma-anther separation did not correlate with seeds per carpel in U flowers (Pearson $r=-0.08$, one-tailed $P=0.38, n=15$ ).

Seed mass also varied among plants and treatments (Table 3, Fig. 1). There was no difference in mass between selfed and outcrossed seeds (grand mean $\pm \mathrm{SE}=0.72 \pm 0.02 \mathrm{mg}$ ). However, seeds from handpollinated flowers (both $\mathrm{S}$ and $\mathrm{X}$ ) were $12 \%$ heavier

(a) Seeds/carpel

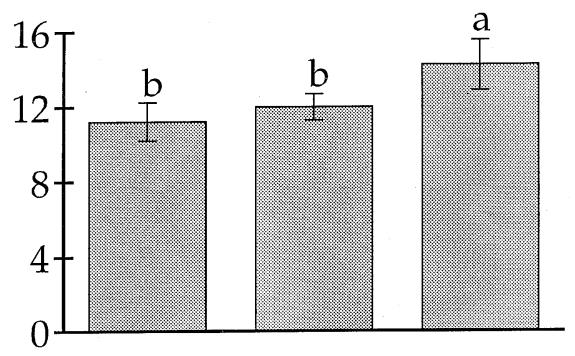

(b) Seed mass (mg)

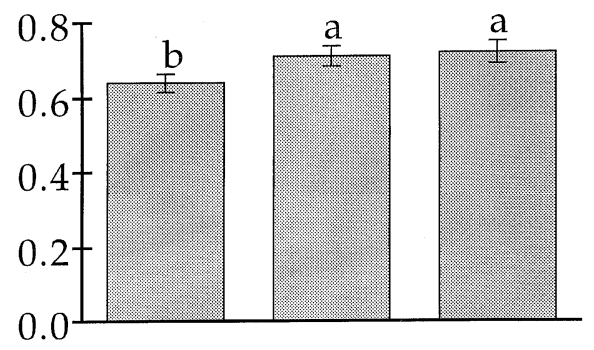

(c) Emergence (\%)

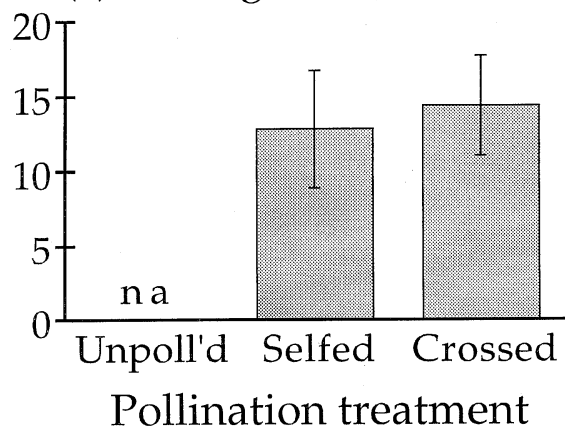

Fig. 1 The number, mass and germination of seeds derived from controlled pollinations in Aquilegia canadensis (population CLR). Bars are means $\pm \mathrm{SE}$. Analysis of seeds/carpel and seed mass is in Table 3. Letters above bars show results from multiple contrasts; those not sharing a letter are significantly different.

(C) The Genetical Society of Great Britain, Heredity, 82, 518-528. 
Table 4 Pollen and ovule production in flowers of Aquilegia canadensis. Statistics are calculated from data from 50 plants. The $r^{2}$ values are from one-way ANOvA with plant as the main effect. All were significant at $P<0.005$

\begin{tabular}{lccrr}
\hline Variable & Range & Mean $\pm \mathrm{SE}$ & $C V$ & $r^{2}$ \\
\hline Carpels/flower & $3.0-5.5$ & $4.8 \pm 0.1$ & $8.8 \%$ & 0.45 \\
Ovules/flower & $70.0-150.7$ & $118.6 \pm 2.2$ & $13.3 \%$ & 0.62 \\
Ovules/carpel & $17.5-31.8$ & $24.8 \pm 0.3$ & $9.9 \%$ & 0.65 \\
Anthers/flower & $27.2-46.0$ & $39.3 \pm 0.5$ & $9.1 \%$ & 0.64 \\
Pollen/flower & $49-97378$ & $71294 \pm 1751$ & $17.2 \%$ & 0.56 \\
Pollen/anther & $1324-2347$ & $1810 \pm 36$ & $20.1 \%$ & 0.53 \\
Pollen/ovule & $455-870$ & $610 \pm 17$ & 0.60 \\
\hline
\end{tabular}

than those from unpollinated flowers. Multiple contrasts revealed significant differences between $\mathrm{X}$ vs. $\mathrm{U}$ $\left(t_{\mathrm{p}}=4.5\right.$, two-tailed $\left.P=0.0002\right)$ and $\mathrm{S}$ vs. $\mathrm{U}$ $\left(t_{\mathrm{p}}=2.9\right.$, two-tailed $\left.P=0.0082\right)$ but not $\mathrm{X}$ vs. $\mathrm{S}$ $\left(t_{\mathrm{p}}=1.4\right.$, two-tailed $\left.P=0.17\right)$.

\section{Pollen and ovule production}

Individual flowers had an average of 39 anthers and 119 ovules (Table 4). There were five carpels in most (79\%) flowers sampled, and an average of 24.8 ovules in each carpel. The average flower contained 71294 pollen grains. The mean pollen/ovule ratio was $610 \pm 17$, which falls between Cruden's (1977) categories of 'facultative autogamy' (mean $\pm \mathrm{SE}=168 \pm 22$ ) and 'facultative xenogamy' ( $797 \pm 88$ ). Thus, the pollen/ ovule ratio for $A$. canadensis is typical of a species that practices a mixture of selfing and outcrossing.

\section{Mating-system variation}

Estimated levels of outcrossing were generally low and varied widely among populations (Table 5 , range of $t_{\mathrm{m}}=0.000-0.828$, average $\left.t_{\mathrm{m}} \pm \mathrm{SE}=0.293 \pm 0.025\right)$. Significant self-fertilization (i.e. $t_{\mathrm{m}}<1$ ) was detected in all 10 populations, whereas significant outcrossing $\left(t_{\mathrm{m}}>0\right)$ was detected in only five. As expected, the proportion of seeds produced through outcrossing was more than twice as high in large than small populations (one-tailed $P<0.001$ ), although there was much variation in $t_{\mathrm{m}}$ among populations within each size class.

Estimates of biparental inbreeding were generally low (Table 5, range of $t_{\mathrm{m}}-t_{\mathrm{s}}=-0.009-0.047$, average $=$ $0.011 \pm 0.003, P=0.003$ ) and significant in only three populations. There was no difference in biparental inbreeding between large and small populations $(P>0.5)$.

Table 5 Estimates $( \pm \mathrm{SE})$ of the multilocus outcrossing rate $\left(t_{\mathrm{m}}\right)$, biparental inbreeding $\left(\mathrm{BI}=t_{\mathrm{m}}-t_{\mathrm{s}}\right)$, parental inbreeding coefficient $(F)$ and inbreeding depression $(\delta)$ for 10 populations of Aquilegia canadensis. Populations are listed in order of decreasing size $(N)$. Averages for large $(N>90)$ and small $(N<40)$ populations are also presented. For $t_{\mathrm{m}}$, BI and $F$, an asterisk indicates estimates significantly greater than zero. Estimates of $\delta$ significantly greater than zero and 0.5 are indicated by * and ${ }^{* *}$, respectively. The average $\delta$ for large populations was calculated excluding the highly unreliable estimate for JUN

\begin{tabular}{lccccc}
\hline Population & $N$ & $t_{\mathrm{m}}$ & BI & $F$ & $\delta$ \\
\hline CLR & 750 & $0.45 \pm 0.08^{*}$ & $0.011 \pm 0.013$ & $0.22 \pm 0.12^{*}$ & $0.54 \pm 0.35^{*}$ \\
WMZ & 200 & $0.66 \pm 0.09^{*}$ & $0.011 \pm 0.016$ & $0.002 \pm 0.14$ & $0.99 \pm 0.73$ \\
AUB & 138 & $0.03 \pm 0.03$ & $-0.009 \pm 0.011$ & $0.31 \pm 0.16^{*}$ & $0.96 \pm 0.07^{* *}$ \\
JUN & 121 & $0.83 \pm 0.09^{*}$ & $0.047 \pm 0.018^{*}$ & $0.42 \pm 0.14^{*}$ & $-4.16 \pm 2.22$ \\
MC1 & 105 & $0.11 \pm 0.06$ & $0.010 \pm 0.005$ & $0.36 \pm 0.19^{*}$ & $0.88 \pm 0.17^{* *}$ \\
MYS & 91 & $0.16 \pm 0.10$ & $0.004 \pm 0.004$ & $0.06 \pm 0.15$ & $0.98 \pm 0.08^{* *}$ \\
MC2 & 40 & $0.00 \pm 0.00$ & $0.000 \pm 0.000$ & $0.60 \pm 0.14^{*}$ & na \\
ANC & 35 & $0.02 \pm 0.02$ & $0.003 \pm 0.002$ & $0.29 \pm 0.14^{*}$ & $0.98 \pm 0.02^{* *}$ \\
CAM & 35 & $0.26 \pm 0.06^{*}$ & $0.025 \pm 0.010^{*}$ & $0.24 \pm 0.12^{*}$ & $0.80 \pm 0.19^{* *}$ \\
BLD & 32 & $0.40 \pm 0.12^{*}$ & $0.006 \pm 0.002^{*}$ & $0.09 \pm 0.18$ & $0.88 \pm 0.37^{*}$ \\
Small & 35 & $0.17 \pm 0.03^{*}$ & $0.008 \pm 0.003^{*}$ & $0.31 \pm 0.07^{*}$ & $0.89 \pm 0.30^{* *}$ \\
Large & 235 & $0.38 \pm 0.03^{*}$ & $0.010 \pm 0.005$ & $0.23 \pm 0.06^{*}$ & $0.87 \pm 0.17^{* *}$ \\
\hline
\end{tabular}

(c) The Genetical Society of Great Britain, Heredity, 82, 518-528. 


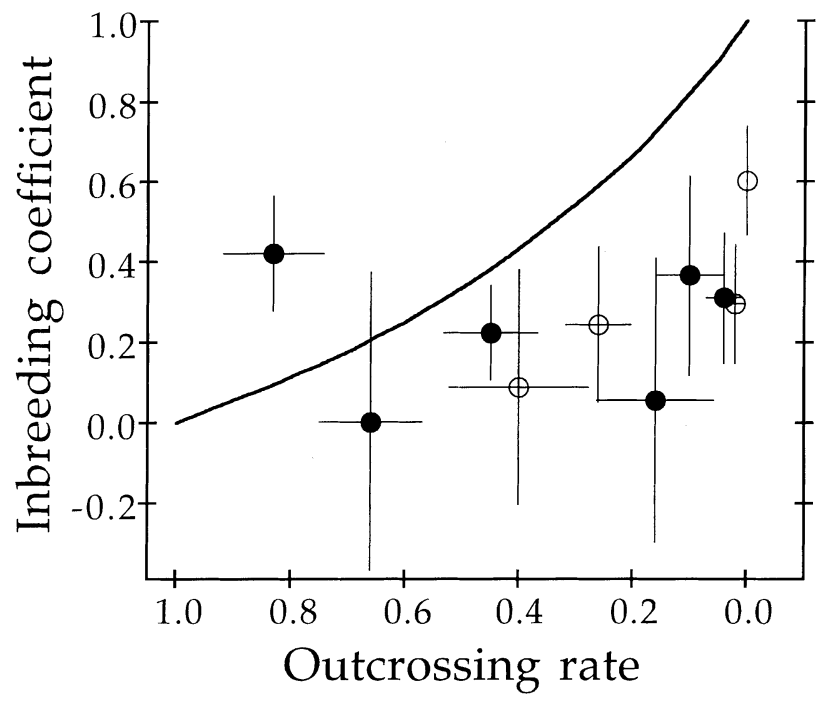

Fig. 2 Comparison of observed parental inbreeding coefficients $(F)$ with those expected at equilibrium with no inbreeding depression for 10 populations of Aquilegia canadensis. Small and large populations are open and closed symbols, respectively. Error bars are $\pm \mathrm{SE}$. The solid line is the expected relation between $t$ and $F$ at inbreeding equilibrium with no inbreeding depression $\left(F_{\mathrm{e}}=[1-t] /[1+t]\right)$. Inbreeding depression causes points to lie below the line.

Parental inbreeding coefficients were substantial and also varied widely among populations (Table 5 , range $=$ $0.002-0.602$, average $F=0.260 \pm 0.048, P<0.001$ ). Estimates of $F$ varied greatly among populations within size classes and the overall difference between classes was not significant (one-tailed $P=0.176$ ). There was also a nonsignificant decrease in $F$ with increasing $t_{\mathrm{m}}$ among populations (Spearman $r_{\mathrm{s}}=-0.43$, one-tailed $P=0.10)$.

\section{Inbreeding depression}

No inbreeding depression was detected for seedling emergence in population CLR (Fig. 1). The percentage of seeds emerging averaged ( \pm SE) $14.1 \pm 2.3 \%$, and did not differ between outcrossed (range $=5-45 \%$, mean $=24.1 \pm 4.2 \%)$ and selfed $(5-69 \%, 19.5 \pm$ $4.6 \%$ ) progenies (paired $t_{\mathrm{p}}=0.7$, one-tailed $P=0.26)$.

Inbreeding depression was also estimated from outcrossing rates $(t)$ and parental inbreeding coefficients $(F)$ for the nine populations for which $t>0$ (Table 5). For eight of these, $F$ was lower than expected at inbreeding equilibrium with no inbreeding depression (Fig. 2). As a result, estimates of $\delta$ were positive and large. Although standard errors for individual estimates were often large, estimates of $\delta$ were significantly greater than zero in seven populations and significantly greater than 0.5 in five. The average $\delta(0.876 \pm 0.140)$ was also significantly greater than $0.5(P<0.0001)$.

\section{Discussion}

Aquilegia canadensis is highly self-compatible and autofertile. Self-pollinations resulted in $85 \%$ as many seeds as outcross pollinations, and isolated, unmanipulated flowers set as many seeds as hand self-pollinated flowers. These results confirm earlier work on this species showing very high levels of autofertility (Macior, 1978; Eckert \& Schaefer, 1998). Self-compatibility and autofertility have also been demonstrated in four other species of Aquilegia (Miller, 1978, 1985; Miller \& Willard, 1983; Brunet \& Eckert, 1998), suggesting that these may be common features of the genus.

Substantial autofertility combined with negligible protogyny in A. canadensis (C. G. Eckert \& K. Mavraganis, unpubl. ms.) ensures that ovules will be selffertilized unless outcross pollen is promptly delivered to stigmas when they become receptive. Low levels of outcrossing (mean $=29 \%$ ) and high parental inbreeding coefficients (mean $=0.26$ ) indicate that the rate of cross-pollination in natural populations may be low and, as a result, the mating system of $A$. canadensis is dominated by self-fertilization.

\section{Variation in outcrossing among populations}

This study revealed extremely wide variation in outcrossing among populations of $A$. canadensis in eastern Ontario (range $=0-83 \%$ ). Extensive variation in the mating system reported for several other species is associated with striking differences in floral morphology and/or development among populations. Outcrossing has been shown to be positively correlated with the degree of protandry in Gilia achilleifolia (range of $t=15-96 \%, n=7$ populations, Schoen, 1982), with herkogamy in Turnera ulmifolia $(0-69 \%, n=12$, Belaoussoff \& Shore, 1995), and with both protandry and herkogamy in Clarkia tembloriensis (3-87\%, $n=7$, Holtsford \& Ellstrand, 1992). In tristylous Eichhornia paniculata, outcrossing correlated negatively with the frequency of self-fertilizing, homostylous phenotypes $(0-96 \%, n=32$, Barrett \& Husband, 1990).

In contrast, there was no conspicuous variation in floral morphology among the populations of $A$. canadensis examined in this study. Differences among populations in the spatial separation of stigmas and anthers during anther dehiscence (herkogamy) might potentially cause variation in self-pollination in A. canadensis (Eckert \& Schaefer, 1998). Moreover, there is considerable phenotypic variation in herkogamy 
among plants within populations $(0-10 \mathrm{~mm})$. However, there seems to be little differentiation among populations for this trait. A survey of herkogamy in 22 eastern Ontario populations including some of the populations examined in this study revealed that only $14 \%$ of the total variation in herkogamy occurred among populations (range of population means $=2.2-4.7 \mathrm{~mm}$; C. G. Eckert \& K. Mavraganis, unpubl. data). This modest variation in floral morphology is unlikely to have contributed much to the wide variation in outcrossing observed among populations.

It is also conceivable that variation among populations in the relative timing of stigma receptivity and anther dehiscence may have contributed to populationlevel variation in outcrossing. Unfortunately, quantifying the degree of dichogamy is difficult in A. canadensis because the onset of stigma receptivity is not reliably indicated by any morphological change to the stigma surface. However, data on variation in pollen deposition and pollen tube growth across floral development from six populations strongly suggest that $A$. canadensis is uniformly adichogamous in eastern Ontario (C. G. Eckert \& K. Mavraganis, unpubl. ms.).

Some of the variation in outcrossing $(t)$ in $A$. canadensis appears to be associated with variation in population size $(N)$. The average $t$ in populations with 40 or fewer flowering plants was only half that $(17 \%)$ of populations with more than 90 plants (38\%). However, the association between $t$ and $N$ was not very strong and there was considerable variation in $t$ among populations within size classes. Although covariation between $N$ and $t$ has been detected in largely homostylous, autofertile populations of Eichhornia paniculata (Barrett \& Husband, 1990), surveys in self-compatible species that lack automatic self-pollination have revealed very limited variation in $t$ in spite of substantial variation in $N$ (Burdon et al., 1988; Van Treuren et al., 1993; Eckert \& Barrett, 1994b; Kennington \& James, 1997).

The mechanism underlying the observed difference in outcrossing between small and large populations cannot be identified at this point. Presumably, there are fewer potential coflowering pollen donors and consequently reduced opportunities for cross-pollination in small than in large populations (Lloyd, 1980). In addition, nectar availability probably increases with $N$, so that plants in large populations may experience more frequent and reliable pollinator visitation than those in small populations (e.g. Sih \& Baltus, 1987). It is also possible that $N$ correlates with some unmeasured variable that directly influences $t$. For instance, plant density, which could be higher in large populations, has been shown to correlate positively with $t$ in some animal-pollinated species (e.g. Murawski, 1991). Although we did not quantify plant density, our field observations suggest that there was little or no covariation between $N$ and density among our sample of populations. There also did not appear to be any major differences in habitat between small and large populations in this study. Ultimately, experimental manipulation of population size will be required to confirm the direct influence of $N$ on $t$ (e.g. Van Treuren et al., 1993).

\section{Inbreeding depression}

The ecological and evolutionary consequences of selffertilization depend strongly on the relative fitness of selfed offspring compared to their outcrossed counterparts. In the populations we studied, parental inbreeding coefficients $(F)$ were usually much lower than expected given the substantial levels of self-fertilization (Fig. 2). Accordingly, inferential estimates of inbreeding depression ( $\delta=1-$ relative fitness of selfed progeny), which include differential survival from seed to reproductive maturity, were usually large and statistically significant (Table 5). Overall, these results suggest that outcrossed offspring survive to reproduce more than ten times as often as selfed progeny (mean $\delta=0.88$ ). This conclusion contrasts somewhat with the lack of difference in emergence between selfed and outcrossed seeds observed under greenhouse conditions (Fig. 1). However, the contrast is less surprising considering that the genetic estimates of $\delta$ include negative effects of inbreeding on survival that occur throughout the life cycle in the natural habitat. Data on single life-cycle components obtained in relatively benign greenhouse environments are liable to underestimate the strength of inbreeding depression (Husband \& Schemske, 1996).

Our main goal in applying Ritland's (1990) equilibrium estimator of $\delta$ was to combine data from several populations to come up with a rough estimate of inbreeding depression for $A$. canadensis, at least in the north-eastern part of its geographical range. The main conclusion from this analysis is that inbreeding depression is very strong, despite high levels of self-fertilization. However, there are two key assumptions underlying Ritland's (1990) approach that must be assessed with respect to this conclusion. First, it is assumed that, on average, Ontario populations are at inbreeding equilibrium. In particular, inbreeding depression could be overestimated if the populations in this region had recently experienced a large increase in the level of self-fertilization. Although this assumption is impossible to test directly, there is no evidence for a recent large-scale shift in the mating system in this species (see Eckert \& Barrett, 1994c for more discussion of this assumption). Secondly, the estimator assumes that $t$ and $F$ do not fluctuate widely between years within populations. In a perennial species like $A$. canadensis, 
this is analogous to assuming that individual populations are at inbreeding equilibrium. This assumption could be supported by a negative correlation between $t$ and $F$ among populations. However, the relation between $t$ and $F$ observed among the populations studied here, though negative (Fig. 2), was not significant. Moreover, the wide variation we observed in $t$ among populations in the absence of any major variation in floral morphology suggests that year-to-year variation in $t$ may be considerable, and we are currently investigating this. However, violation of this assumption does not cast much doubt on our main conclusion. Simulations by Ritland (1990) indicate that the net result of temporal variation in $t$ is a downward bias in $\delta$. Thus, inbreeding depression may be stronger than estimated.

Theoretical models examining the maintenance of genetic load generally predict that inbreeding depression declines with chronic self-fertilization (e.g. Charlesworth \& Charlesworth, 1987). Although a weak negative relation between self-fertilization and inbreeding depression is generally observed among plant species (Husband \& Schemske, 1996), the results of this study join those from a wide variety of plant taxa in demonstrating strong inbreeding depression in populations with substantial levels of chronic self-fertilization (Husband \& Schemske, 1996).

\section{Ecological consequences of self-fertilization}

The results of this study support the widely held but rarely tested expectation that reduced $N$ may cause increased self-fertilization in self-compatible hermaphrodites (Ellstrand \& Elam, 1993). Although the relation between $N$ and $t$ was not particularly strong among the populations examined here, on average, small populations did outcross at a lower level than large populations. Variation in outcrossing coupled with strong inbreeding depression may lead to substantially reduced viability in small compared to large populations. In fact, a concurrent study of variation in fitness among populations revealed a positive association between $N$ and reproductive output in populations of $A$. canadensis from eastern Ontario, including the populations studied here (K. Mavraganis \& C. G. Eckert, unpubl. ms.). Plants in small populations had fewer flowers per plant and ovules per flower and lower fruit-set than those in large populations.

The results of the present study appear to provide a mechanism underlying the covariation between $N$ and fitness in $A$. canadensis. However, a causal link between population fitness and the mating system is impossible to verify on the basis of correlations alone. The relation between fitness and $N$ may result from one or some combination of several factors. For example, if populations were small because they occurred in poor-quality habitat, then large populations might be more fecund than small populations simply because of differences in habitat quality. Of course, the effect of habitat and the mating system need not be mutually exclusive. Covariation between $N$ and habitat quality might also amplify the effect of variation in $t$ by increasing the fitness differential between selfed and outcrossed offspring. Ultimately, the contribution of mating-system variation to variation in population fitness must be verified experimentally. For instance, if the viability of naturally pollinated and hand-outcrossed progeny from large and small populations were compared in a common environment, we expect that outcrossed progeny should outperform naturally pollinated progeny to a greater extent in small than large populations.

\section{Evolution of self-fertilization}

High levels of self-fertilization in species with strong inbreeding depression present a challenge for most theoretical models of mating-system evolution. From a genetic standpoint, the level of inbreeding depression estimated for $A$. canadensis in this study would seem more than sufficient to balance the twofold genetransmission advantage of self-fertilization (Lloyd, 1992). What then is the adaptive significance of such high levels of selfing in $A$. canadensis?

Autonomous self-fertilization may be advantageous in spite of inbreeding depression if it allows individuals to produce seed when pollinators and/or potential mates are scarce (Lloyd, 1992). Reproductive assurance may be an important selective advantage because seasonal seed production in plant populations is often limited by pollen availability (Burd, 1994). It would seem important in A. canadensis because this species typically occurs in small, patchy populations, and flowers in the spring when pollinator visitation may be low during bouts of inclement weather. However, the evidence to date suggests that the reproductive assurance provided by selfing does not increase fitness in A. canadensis.

Eckert \& Schaefer (1998) showed that, in the area around and including population WMZ, flowers emasculated to prevent automatic selfing set as many seeds as intact flowers, even at low plant densities. Because emasculated flowers seemed to receive sufficient pollen for full seed-set, automatic selfing probably results in severe seed discounting rather than reproductive assurance (Lloyd, 1992). Nevertheless, this study examined only a single population during one flowering season, and broader sampling of populations and flowering seasons is clearly required. If it turns out that selfing does increase seed-set, demographic analysis will be required to determine 
whether selfed offspring make any contribution to parental fitness in the face of strong inbreeding depression and whether the benefit of increased seasonal reproductive output outweighs the potential cost of reduced survival to and fecundity during future reproductive seasons (Morgan et al. 1997).

\section{Acknowledgements}

We thank Grace Lo, Blandine Massonnet, Pascal Thomas and especially Greg Grabas for help with the fieldwork; the Queen's University Biological Station and the Saint Lawrence Islands National Park for logistic support in the field and access to study sites; Marcel Dorken, Vicki Friesen and Brian Husband for comments on the manuscript; Queen's University School of Graduate Studies for graduate awards to K.M.; and the Natural Sciences and Engineering Research Council of Canada (NSERC) for a research grant to C.G.E.

\section{References}

BARRETT, S. C. H. 1990. Mating system evolution and speciation in heterostylous plants. In: Otte, D. and Endler, J. A. (eds) Speciation and its Consequences, pp. 257-283. Sinauer, Sunderland, MA.

BARRETT, S. C. H. AND HUSBAND, B. C. 1990. Variation in outcrossing rates in Eichhornia paniculata: The role of demographic and reproductive factors. Pl. Sp. Biol., 5, 41-55.

BELAOUSSOFF, S. AND SHORE, J. S. 1995. Floral correlates and fitness consequences of mating system variation in Turnera ulmifolia. Evolution, 49, 545-556.

BIJLSMA, R., OUBORG, N. J. AND VAN TREUREN, R. 1994. On genetic erosion and population extinction in plants: a case study in Scabiosa columbaria and Salvia pratensis. In: Loeschcke, V., Tomuik, J. and Jain, S. (eds) Conservation Genetics, pp. 255-272. Birkhäuser, Basel, Switzerland.

BROWN, A. H. D. 1990. Genetic characterization of plant mating systems. In: Brown, A. H. D., Clegg, M. T., Kahler, A. L. and Weir, B. S. (eds) Plant Population Genetics, Breeding, and Genetic Resources, pp. 145-162. Sinauer, Sunderland, MA.

BRUNET, J. AND ECKERT, C. G. 1998. Effect of floral morphology and display on outcrossing in blue columbine, Aquilegia caerulea (Ranunculaceae). Funct. Ecol., 12, 596-606.

BURD, M. 1994. Bateman's principle and plant reproduction: the role of pollen limitation in fruit and seed set. Bot. Rev., 60, 83-139.

BURDON, J. J., JAROSZ, A. M. AND BROWN, A. H. D. 1988. Temporal patterns of reproduction and outcrossing in weedy populations of Echium plantagineum. Biol. J. Linn. Soc., 34, 81-92.

CHARLESWORTH, B. 1992. Evolutionary rates in partially selffertilizing species. Am. Nat., 140, 126-148.

CHARLESWORTH, D. AND CHARLESWORTH, B. 1987. Inbreeding depression and its evolutionary consequences. Ann. Rev. Ecol. Syst., 18, 237-268.
CRUDEN, R. W. 1977. Pollen-ovule ratios: a conservative indicator of breeding systems in flowering plants. Evolution, 31, 32-46.

CRUDEN, R. W. AND LYON, D. L. 1989. Facultative xenogamy: Examination of a mixed mating system. In: Bock, J. H. and Linhart, Y. B. (eds) The Evolutionary Ecology of Plants, pp. 171-208. Westview Press, Boulder, CO.

ECKERT, C. G. AND BARRETT, S. C. H. 1994a. Self-compatibility, tristyly and floral variation in Decodon verticillatus (Lythraceae). Biol. J. Linn. Soc., 53, 1-30.

ECKERT, C. G. AND BARRETT, S. C. H. 1994b. Post-pollination mechanisms and the maintenance of outcrossing in selfcompatible Decodon verticillatus (Lythraceae). Heredity, $\mathbf{7 2}$, 396- 411.

ECKERT, C. G. AND BARRETT, S. C. H. 1994c. Inbreeding depression in partially self-fertilizing Decodon verticillatus (Lythraceae): population genetic and experimental analyses. Evolution, 48, 952-964.

ECKERT, C. G. AND SCHAEFER, A. 1998. Does self-pollination provide reproductive assurance in wild columbine, Aquilegia canadensis (Ranunculaceae) ? Am. J. Bot., 85, 919-924.

Ellstrand, N. C. AND ELAM, D. R. 1993. Population genetic consequences of small population size: implications for plant conservation. Ann. Rev. Ecol. Syst., 24, 217-242.

GRANT, K. A. AND GRANT, v. 1968. Hummingbirds and Their Flowers. Columbia University Press, New York.

HAMRICK, J. L. AND GODT, M. J. 1990. Allozyme diversity in plant species. In: Brown, A. H. D., Clegg, M. T., Kahler, A. L. and Weir, B. S. (eds) Plant Population Genetics, Breeding, and Genetic Resources, pp. 43-63. Sinauer, Sunderland, MA.

HOLTSFORD, T. P. AND ELLSTRAND, N. C. 1992. Genetic and environmental variation in floral traits affecting outcrossing rate in Clarkia tembloriensis (Onagraceae). Evolution, 46, 216-225.

HUSBAND, B. C. AND SCHEMSKe, D. W. 1996. Evolution of the magnitude and timing of inbreeding depression in plants. Evolution, 50, 54-70.

KENNINGTON, w. J. AND JAMES, S. H. 1997. The effect of small population size on the mating system of a rare clonal mallee, Eucalyptus argutifolia (Myrtaceae). Heredity, 78, 252-260.

LLOYD, D. G. 1980. Demographic factors and mating patterns in angiosperms. In: Solbrig, O. T. (ed.) Demography and Evolution in Plant Populations, pp. 67-88. Blackwell Scientific Publications, Oxford.

LLOYD, D. G. 1992. Self- and cross-fertilization in plants. II. The selection of self-fertilization. Int. J. Plant Sci., 153, 370-380.

MACIOR, L. W. 1978. The pollination of vernal angiosperms. Oikos, 30, 452-460.

MILlER, R. B. 1978. The pollination ecology of Aquilegia elegantula and A. caerulea (Ranunculaceae) in Colorado. Am. J. Bot., 65, 406-414.

MILleR, R. B. 1985. Hawkmoth pollination of Aquilegia chrysantha (Ranunculaceae) in southern Arizona. Southwest Nat., 30, 69-76.

MILLER, R. B. AND WILLARD, C. L. 1983. The pollination ecology of Aquilegia micrantha (Ranunculaceae) in Colorado. Southwest Nat., 28, 157-164. 
MORGAN, M. T., SCHOEN, D. J. AND Bataillon, T. M. 1997. The evolution of self-fertilization in perennials. Am. Nat., 150, 618-638.

MURAWSKI, D. A. 1991. The effect of density of flowering individuals on the mating system of nine tropical tree species. Heredity, 67, 167-174.

Neter, J., WASSERman, W. AND KutNer, M. H. 1990. Applied Linear Statistical Models, 3rd edn. Richard D. Irwin, Homewood, NJ.

RITLAND, K. 1986. Joint maximum likelihood estimation of genetic and mating structure using open-pollinated progenies. Biometrics, 42, 25-43.

RITLAND, K. 1990. Inferences about inbreeding depression based on changes of the inbreeding coefficient. Evolution, 44, 1230-1241.

SCHEMSKe, D. W., HUSBAND, B. C., RUCKLEShAUS, M. H., GOODWILlE, C., PARKER, I. M. AND BISHOP, J. G. 1994. Evaluating approaches to the conservation of rare and endangered plants. Ecology, 75, 584-606.

SCHNECK, J. 1901. Notes on Aquilegia canadensis (L.) and $A$. vulgaris (L.). Bot. Gaz., 32, 304-305.

SCHOEN, D. J. 1982. The breeding system of Gilia achilleifolia: variation in floral characteristics and outcrossing rate. Evolution, 36, 352-360.

SIH, A. AND BALTUS, M. 1987. Patch size, pollinator behavior and pollinator limitation in catnip. Ecology, 68, 1679-1690.

VAN TREUREN, R., BIJLSMA, R., OUBORG, N. J. AND VAN DELDEN, w. 1993. The effects of population size and plant density on outcrossing rates in locally endangered Salvia pratensis. Evolution, 47, 1094-1104.

WENDEL, J. F. AND WEEDEN, N. F. 1991. Visualization and interpretation of plant isozymes. In: Soltis, D. E. and Soltis, P. S. (eds) Isozymes in Plant Biology, pp. 5-45. Dioscorides Press, Portland, OR. 